
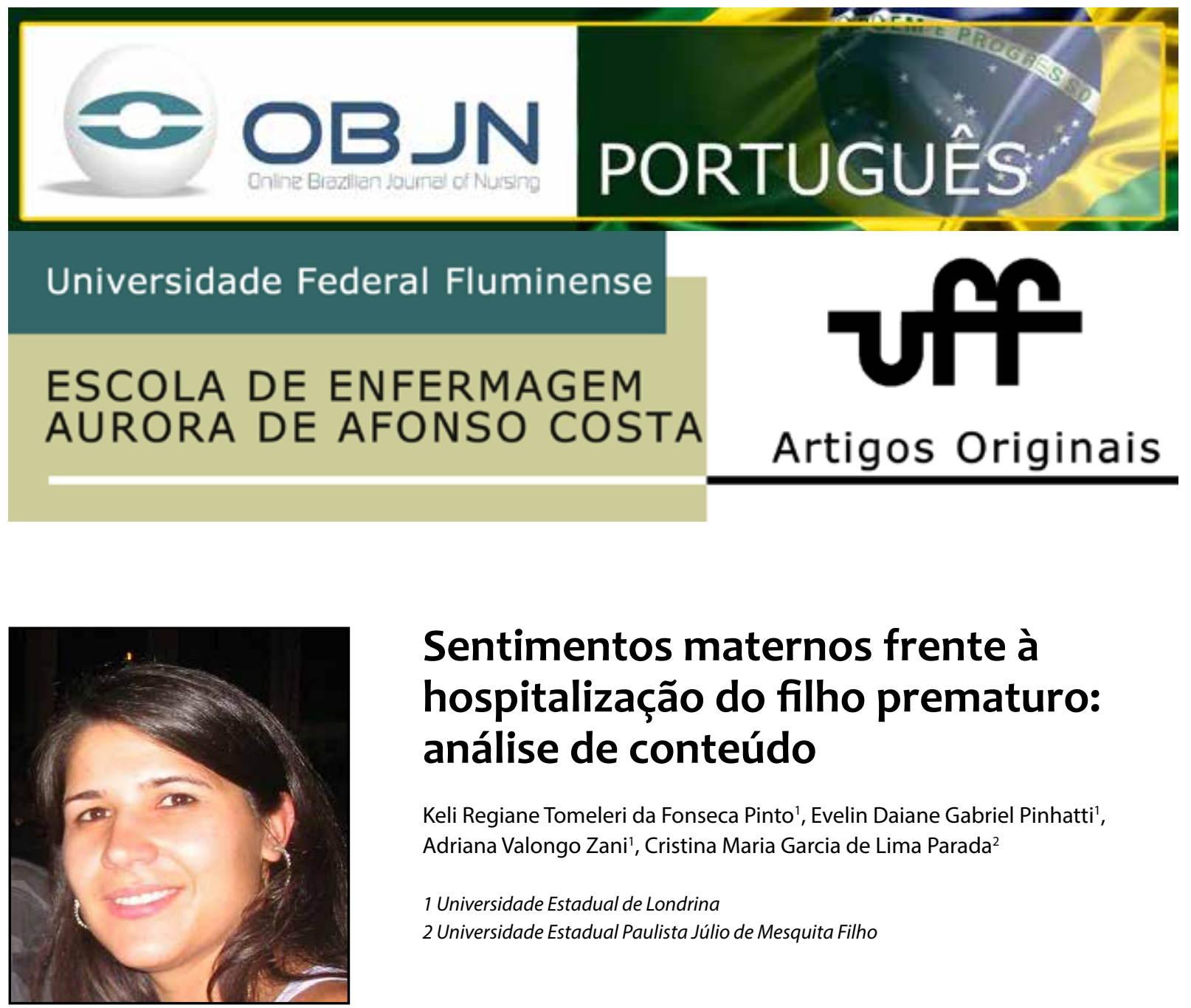

\title{
Sentimentos maternos frente à hospitalização do filho prematuro: análise de conteúdo
}

\author{
Keli Regiane Tomeleri da Fonseca Pinto', Evelin Daiane Gabriel Pinhatti', \\ Adriana Valongo Zani' ${ }^{1}$ Cristina Maria Garcia de Lima Parada² \\ 1 Universidade Estadual de Londrina \\ 2 Universidade Estadual Paulista Júlio de Mesquita Filho
}

\section{RESUMO}

Objetivo: compreender os sentimentos vivenciados pela mãe ao ter seu filho prematuro internado em Unidade de Terapia Intensiva Neonatal (UTIN). Método: pesquisa descritiva de natureza qualitativa, realizada com 11 mães, por meio de entrevista semiestruturada. Adotou-se o referencial da Análise de Conteúdo. Resultados: identificaram-se três categorias temáticas: Sofrimento frente à hospitalização do filho prematuro; O cuidado ao filho prematuro: confiança na equipe; Experienciando o impacto do ambiente de terapia intensiva neonatal. Discussão: as mães depararam-se com sentimentos como o medo, culpa pelo sofrimento e possível perda do filho, e referiram sentir-se impotentes e incapazes de cuidar do filho neste momento, o que aumentou suas angústias. Conclusão: as mães, ao se depararem com o filho prematuro na UTIN, vivenciaram sentimentos diversos, sentindo-se incapazes e, muitas vezes, afastando-se do recém-nascido. Contudo, relataram confiança e segurança no cuidado dos profissionais com seus filhos, valorizando tanto aspectos técnicos quanto as relações interpessoais.

Descritores: Relações Mãe-Filho; Unidade de Terapia Intensiva Neonatal; Recém-Nascido Prematuro. 


\section{INTRODUÇÃO}

A mulher, ao se tornar mãe, possui capacidade imensurável de formar vínculos duradouros com seus filhos, situação emocional denominada apego, que impulsiona a mãe a oferecer condições facilitadoras ao crescimento e desenvolvimento do filho, com implicações físicas e emocionais ao longo da vida ${ }^{(1)}$.

O início do apego ao filho ocorre durante a gravidez, porém, continua e se intensifica após o nascimento e ao longo de todas as interações que ocorrerão. Geralmente, as mães esperam sentir-se naturalmente vinculadas aos bebês logo após o nascimento. No entanto, não se trata de algo automático e, para favorecer sua ocorrência, deve haver oportunidades de contato da mãe com o filho, evitando-se situações que limitem ou interfiram neste processo ${ }^{(2)}$.

A gestação é um importante período de preparação para a chegada do bebê, parte de experiência repleta de sentimentos intensos e transformações físicas e emocionais. É, também, momento de regressão à dependência, no qual a mãe começa a desenvolver o processo de identificação com o filho que vai nascer. Ela se torna anfitriã de um novo ser humano e precisa recebê-lo sem saber como ele será, pois é, até então, um bebê desconhecido. Assim, costumam gerar expectativas quanto à criança(3).

Nas situações em que a chegada do filho é antecipada, não acontecendo como sonhado pela mãe e sua família, muitos sentimentos são aflorados. Normalmente, o parto prematuro ocorre de forma urgente, o que faz com que a mãe não se veja preparada psicologicamente, sentindo-se também prematura como mãe e, muitas vezes, não pronta para cuidar do seu filho, tendendo a reagir de formas diversas a essa situação. Surge o medo da doença, do desconhecido, do ambiente hospitalar e a incerteza quanto ao presente e ao futuro do seu familiar, isto é, da evolução clínica do bebê e de sua sobrevivência(4).

Quando o recém-nascido pré-termo necessita de cuidados na Unidade de Terapia Intensiva Neonatal (UTIN), o que ocorre frequentemente, a situação é ainda mais complexa. Isto porque a mãe passa a ser mera expectadora dos cuidados especializados prestados pela equipe de saúde a seu filho, podendo ocasionar o sentimento de perda de sua função materna e gerando dificuldade em reconhecer-se como mãe. $\mathrm{O}$ ambiente desconhecido da UTIN, que é cercado por tecnologia, com aparelhos de última geração, pode aumentar o medo e a insegurança da mã $\mathrm{e}^{(5)}$.

Nos partos prematuros, por vezes, o recém-nascido necessita de atendimento imediato na sala de parto, antes de ser encaminhado à UTIN, sendo o contato extrauterino com a mãe adiado em decorrência das suas condições e de normas/ rotinas institucionais. No caso do nascimento pré-termo, devido à condição de imaturidade biológica, o bebê que nasce é frágil, sonolento, imprevisível e imaturo, sendo necessário encaminhá-lo imediatamente a UTIN e, portanto, esta separação, normalmente, é total no primeiro dia e parcial nos dias subsequentes ${ }^{(6)}$.

Pelo exposto, o nascimento prematuro é acontecimento inesperado na vida da família, configurando-se como evento estressante, que gera, principalmente para os pais, distintos tipos de emoções e sentimentos, como ansiedade, angústia, culpa e decepção. A chegada de um bebê pequeno e frágil deixa uma lacuna entre a expectativa do bebê imaginário, aquele que ao engravidar se sonhava com características físicas saudáveis, e o bebê real, presente na UTIN. Este fato leva a maioria das mães a se sentir insegura quanto à capacidade de cuidar, de maternar e interagir com o bebê $\hat{e}^{(7)}$.

Buscando conhecer melhor a realidade vivenciada e os sentimentos da mãe em situação de separação de seu filho após o parto, propôs- 
-se o presente estudo, que tem por objetivo compreender os sentimentos vivenciados pela mãe ao ter seu filho prematuro internado em UTIN.

\section{MÉTODO}

Utilizou-se a abordagem qualitativa, adotando-se o referencial da análise de conteúdo segundo Bardin ${ }^{(8)}$. A pesquisa qualitativa é entendida como aquela que envolve questões subjetivas, que não se preocupa em quantificar, mas sim em compreender e explicar a dinâmica das relações sociais. Ela trabalha com o universo de significados, motivos, aspirações, crenças, valores e atitudes, que não podem ser reduzidos à operacionalização de variáveis ${ }^{(9)}$. A análise de conteúdo possibilita desvelar o que está por trás das palavras, possibilitando a interpretação(8).

Constituiu-se cenário do estudo a UTIN localizada em um hospital credenciado pelo Sistema Único de Saúde (SUS), sendo um serviço público considerado como Centro Regional de Referência, com modelo de cuidado direcionado às gestantes de alto risco. Trata-se de um hospital de grande porte, que atende pacientes de aproximadamente 250 municípios do Paraná e de mais de 100 municípios de outros estados, e é integrante da rede estadual de saúde ${ }^{(10)}$.

Participaram deste estudo 11 mães que tiveram filhos prematuros hospitalizados na UTIN. Foram considerados critérios de inclusão: mães de recém-nascidos com idade gestacional menor que 37 semanas e cujos filhos necessitaram de hospitalização na UTIN. Foram excluídas as mães cujos filhos foram à óbito no período da coleta e/ou possuíam malformações.

As mães, ao serem convidadas pessoalmente pelas pesquisadoras a participarem da pesquisa, foram informadas sobre os objetivos do estudo, a garantia de sigilo das informações, a participação espontânea e a liberdade de se retirarem da pesquisa a qualquer momento. Nessa ocasião também foi solicitada autorização para a gravação da entrevista. A participação foi assentida por meio da assinatura de termo de consentimento livre e esclarecido.

A coleta de dados foi realizada no período de agosto a setembro de 2013, por meio de entrevista semiestruturada, compreendida como um processo de interação social, na qual o entrevistador busca obter informações sobre o entrevistado, a partir de roteiro contendo tópicos em torno de um problema central. Além disso, privilegia a obtenção de informações pela fala individual, revelando condições estruturais, sistemas de valores, normas e símbolos, e transmite, a partir de um porta-voz, representações sobre determinados grupos ${ }^{(11)}$.

A questão utilizada para nortear a entrevista foi: O que significa para você ter seu filho prematuro internado na UTIN?

Além da gravação, foi utilizado caderno de campo para registro de síntese das falas. Ao término da entrevista, a mãe ouvia a gravação e o pesquisador lia a síntese realizada, para validação ou alteração das informações. As entrevistas foram individuais e realizadas em espaço reservado da UTIN. A duração média do encontro das pesquisadoras com as mães foi de 45 minutos, considerando a interação inicial e a entrevista propriamente dita. $\mathrm{O}$ número de mães não foi definido a priori: a coleta de dados foi encerrada no momento em que as inquietações foram respondidas e o objetivo do estudo alcançado.

Após a coleta de dados, realizou-se a transcrição das entrevistas e a exploração do material, identificando os núcleos temáticos, conforme estabelece o método de análise de conteúdo proposto por Bardin ${ }^{(8)}$. Para preservar o anonimato das mães participantes, elas foram identificadas pela letra $M$, seguida pelo número correspondente a ordem da entrevista. 
Esta pesquisa foi realizada mediante parecer favorável do Comitê de Ética em Pesquisa da Universidade Estadual de Londrina (UEL), sob nº CEP 331/2011.

\section{RESULTADOS}

Breve caracterização das 11 mães participantes do estudo evidencia que em relação ao número de gestações seis eram primíparas. A idade variou entre 17 e 41 anos. Quanto à situação conjugal, nove eram casadas e duas viviam em união consensual. A renda familiar variou entre um e cinco salários mínimos. Cinco realizaram parto vaginal e seis foram submetidas à cesárea, apresentando idade gestacional que variou de 24 a 35 semanas. O peso dos recém-nascidos ao nascer variou entre 560 e 2.190 gramas.

Ao analisar as informações obtidas durante as entrevistas, foi possível organizá-las em três categorias temáticas: Sofrimento frente à hospitalização do filho prematuro; O cuidado ao filho prematuro: confiança na equipe; Experienciando o impacto do ambiente de terapia intensiva neonatal.

\section{Sofrimento frente à hospitalização do filho prematuro}

As mães, ao se depararem com o filho na UTIN, vivenciaram sentimentos diversos, tais como: medo, tristeza por não poder pegar o filho no colo, culpa e saudade da proximidade, o que se torna frustrante para a mãe.

Eu senti um pouquinho de medo [...] chegar em casa sem ele (choro) [...], saudade dele, de querer estar com ele, eu planejei o quartinho, as coisinhas dele, e não pude levar [...]. Eu sempre imaginei ir para a maternidade ganhar o neném, dar banho, levar embora [...]. (M5)

\begin{abstract}
Ah, eu senti um peso, uma tristeza, eu queria ter saído com ela já, ganhado e ter ido embora com ela, mas é a natureza dela, fazer o que, né? (M8)
\end{abstract}
[...] foi difícil, dá um sentimento de culpa, de impotência nas primeiras horas [...]. Porque nunca tinha visto, nem por vídeo, nada [...] uma criança prematura. Então, eu estranhei, num primeiro momento, mas depois eu já fui aceitando. (M7)

As mães do estudo relataram que ao se depararem com a fragilidade de seus filhos, monitorados com aparelhos desconhecidos, vivenciaram sentimentos de sofrimento, sensação de impotência, insegurança para realizar um toque ou cuidado, sentindo-se incapazes e afastando-se, muitas vezes, do recém-nascido.

$$
\begin{aligned}
& \text { O tamanho é um pouco frágil, a respira- } \\
& \text { ção, você coloca a mão e você sente o } \\
& \text { coração, parece que é tudo superficial } \\
& \text { [...] na cabeça você sente a circulação, } \\
& \text { tudo tão fininho, parece uma casqui- } \\
& \text { nha de ovo. (M1) }
\end{aligned}
$$

Nunca imaginava vê-lo daquele tamanhinho [...] muito pequenininho, $\mathrm{e}$, assim, é surpresa ver que ela é perfeita, sabe? Tem cabelo, unha, cílios, tem tudo, só estava ali para crescer mesmo, estava tudo no devido lugarzinho. (M6)

A situação da criança tão pequenininha, pesando gramas, é difícil; no começo dá certo medo, um desespero. (M2) 
[...] Achei a Rafaela muito estranha, ainda não tinha caído nem a ficha que eu tinha engravidado, que eu tinha ganhado ela [...] não era minha menininha, tinha aspecto de japonesinha, olho puxado, a toca não servia na cabeça [...]. (M8)

[...] Meu ultrassom deu 500 gramas [...], então, 500 gramas não é nem um pacote de feijão, eu sabia que não ia ser uma criança grande. [...] Primeiro, eu esperei 25 dias para pegar o meu filho pela primeira vez, aí que eu comecei a sentir um gostinho de ser mãe, porque, até então, nem relar a mão nele eu relava, porque a oximetria caia só de olhar pra ele, porque era muito miúdo. (M5)

O cuidado ao filho prematuro: confiança na equipe

É possível observar a confiança e segurança das mães em relação aos profissionais de saúde. Os esclarecimentos, a atenção e o acolhimento da equipe de saúde à família do recém-nascido, além do convívio diário, fortalecem essa relação de confiança.

E eles [os profissionais] explicam, sabe, qualquer dúvida [...] eles não fazem nada sem falar para mim dela, e sei que eles a estão tratando bem. (M4)

Todo mundo é excelente, assim, eu acho que estão de parabéns [...] tem a reunião sexta-feira que a gente escolhe um tema para tirar as dúvidas, por que são vários procedimentos que o neném passa, que para gente é coisa de outro mundo e para eles é simples, aí eles explicam e a gente fica mais tranquilo em relação a isso. (M3)

$\mathrm{O}$ atendimento deles é muito bom! Isso passa segurança para a gente, que a criança está sendo bem assistida. A gente vê a criança se desenvolvendo a cada dia [...] cada dia que passa você vem e a criança está melhor, está mais coradinha, ganhando uns quilinhos, aumentando a quantidade de leite [...] isso vai trazendo mais esperança [...]. (M7)

Pelas falas das mães, evidencia-se o reconhecimento delas quanto à equipe de saúde e o sentimento de que são valorizadas pelos profissionais de saúde.

Experienciando o impacto do ambiente de terapia intensiva neonatal

O ambiente da UTIN, cercado de aparatos tecnológicos, profissionais qualificados, cuidados especiais e termos técnicos, contribui para o aumento da ansiedade e da tensão das mães frente ao desconhecido. Constata-se isso nas falas a seguir:

Chegar lá e ver aquele monte de caninho, cheio daqueles negócios nela parece que está machucando [...]. Quando cheguei na UTI me deu vontade de pegar ela e sair correndo. (M4)

A gente demora doze horas para poder descer e chega lá e vê ele cheio de tubinho no nariz, aí eu chorei... [...]. Mas aí veio a enfermeira conversar com a gente, mas é horrível... Porque, [...] todo mundo pensa que o neném já vai morrer, na verdade não é bem assim, mas 
eu sempre tive essa impressão: 'ah, tá na UTI, vai morrer'. (M3)

[...] eu pensava que o fato de estar aqui, é que não sobreviveria, sabe? [...] ah, mas vendo a competência dos médicos, dos enfermeiros, as outras mães dando testemunho, fui criando força e coragem [...]. (M6)

[...] ela nasceu até bem, respirando sozinha; depois de três dias ela foi intubada [...] é assustador ver tudo aquilo num bebezinho [...]. O lugar, eu nunca tinha visto, eu nem imaginava que existia, uma criança em incubadora, uma UTI infantil... Ainda mais no começo, os equipamentos, o lugar, é tudo muito complicado. (M2)

Para as mães é difícil ver os seus filhos na UTIN ligados a fios e tubos, cercados de cuidados e aparelhos, como demonstraram algumas das falas.

\section{DISCUSSÃO}

O presente estudo permitiu identificar e compreender a variedade de sentimentos vivenciados pela mãe ao ter seu filho prematuro internado em UTIN, relacionados ao sofrimento frente à hospitalização, a confiança na equipe de cuidado e o impacto do ambiente de terapia intensiva neonatal.

As mães depararam-se com sentimentos como o medo, culpa pelo sofrimento e possível perda do filho, e referiram sentir-se impotentes e incapazes de cuidar do filho neste momento, o que aumentou suas angústias.

Estes sentimentos corroboram com os evidenciados em outro estudo ${ }^{(12)}$, cujo objetivo foi identificar, por meio da literatura cientifica, sentimentos vivenciados pela família de recém-nascidos de risco e a relação desta com os profissionais de saúde. Identificou-se que a maioria dos artigos referiu sentimentos de sofrimento, como o medo de perder o filho, culpa e insegurança diante do filho considerado de risco devido à prematuridade e necessidade de hospitalização em unidade de terapia intensiva.

A vivência da hospitalização de uma criança na UTIN é conhecida por ser experiência estressante para os pais. Embora avanços na ciência e na tecnologia tenham auxiliado na melhor qualidade dos níveis de cuidado neonatal, permitindo que prematuros e bebês gravemente doentes sobrevivam, isto não ameniza as experiências emocionais e psicológicas negativas que os pais precisam suportar. As complexidades do ambiente de UTIN e a aparência do filho são potenciais fatores de estresse para os pais ${ }^{(13)}$.

Estes fatores podem influenciar negativamente a capacidade dos pais de aprenderem sobre os cuidados dos seus filhos, gerando sentimentos de incapacidade e frustação(14).

Os sentimentos das mães devem ser valorizados, acompanhados de atendimento humanizado e acolhedor, lembrando que, ao retardar o contato entre a mãe e o prematuro, a situação se agrava para ambos, pois a mãe pode não se sentir segura o suficiente para cuidar do seu bebê em seu domicilio, e o bebê pode necessitar de internações recorrentes pós-alta(7).

Para o adequado desenvolvimento do bebê, é necessário equilíbrio entre as necessidades biológicas, ambientais e familiares. Portanto, faz-se necessária a adequação da abordagem técnica e das posturas que impliquem mudanças ambientais e comportamentais com vistas à maior humanização do atendimento(15). Assim, a equipe foi valorizada pelas mães, não apenas pela competência técnica, mas também pelas relações interpessoais estabelecidas e decor- 
rentes, por exemplo, da valorização da presença materna, respeito as suas dúvidas e orientações sobre os procedimentos a serem realizados.

Sabendo-se da importância do vínculo precoce entre os pais e seus filhos prematuros e/ou hospitalizados em unidades de terapia intensiva, o Ministério da Saúde implantou diretrizes para nortear a equipe a facilitar a formação de vínculos afetivos, como: livre acesso dos pais à UTIN; o direito de terem um profissional para fornecer todas as informações necessárias sobre o bebê; estímulo ao toque e carinho no bebê; tornar o ambiente da UTIN acolhedor para eles; permitir que participem dos cuidados de seus bebês; e escutar atentamente o que têm a dizer; esclarecer as suas dúvidas ${ }^{(15)}$.

Pôde-se observar, neste estudo, que as mães confiavam na equipe da UTIN que assistia a seu filho, o que pode favorecer que os pais desenvolvam precocemente vínculo com seus filhos, pois sentem segurança na equipe no sentido de os auxiliarem a vencer os medos frente às situações vividas ${ }^{(16)}$.

Assim, a comunicação dos profissionais com a família favorece o surgimento de vínculo de confiança e respeito, contribuindo com a qualidade do cuidado prestado ao recém-nascido. É importante que os profissionais forneçam subsídios para a família, a fim de diminuir a ansiedade e o medo que os pais do neonato sentem, oferecendo condições de conforto, tentando responder às preocupações e fornecendo informações sobre o estado de saúde da criança, o tratamento e equipamentos utilizados ${ }^{(16)}$.

O impacto gerado nos pais frente ao aparato tecnológico do ambiente de uma UTIN é assustador. De modo geral, os pais desconhecem este ambiente e, a princípio, apresentam sentimento de sofrimento por observar que toda esta tecnologia pode estar gerando dor e sofrimento em seu filho. Os pais ao adentrarem a unidade e se depararem com seu filho pequeno, frágil, conectado a diversos circuitos e tubos, sentem-se impotentes por não poderem reverter esta situação ${ }^{(12)}$.

Em estudo ${ }^{(17)}$ referente à experiência de mães de bebês prematuros hospitalizados em unidades de terapia intensiva, resultados semeIhantes foram obtidos quando se considerou o impacto do ambiente hospitalar, visto que os principais sentimentos revelados foram o medo e o estresse causado pelo desconhecimento do ambiente.

O estresse que resulta do nascimento prematuro, da necessidade de cuidados intensivos e da separação física prolongada devido à necessidade de hospitalização na UTIN, pode causar efeitos adversos fisiológicos e psicológicos, tanto para o bebê quanto para a mãe. O ambiente hospitalar e esta nova situação comprometem o estabelecimento e a manutenção da relação mãe-bebê e pode repercutir no desenvolvimento posterior da criança e no bem-estar emocional da mãe. Portanto, são importantes a comunicação proficiente, a boa provisão de informações e o suporte sensível e emocional, no intuito de superar ou reduzir os efeitos do impacto da hospitalização e dos aparatos tecnológicos utilizados $^{(18-19)}$.

A equipe da UTIN deve acolher os pais para que eles se sintam integrados ao ambiente, proporcionando empatia, esclarecimento quanto às condições clínicas da criança, orientação sobre os procedimentos e aparelhos presentes no ambiente, diminuindo, assim, a visão de um ambiente hostil e assustador ${ }^{(20)}$.

\section{CONCLUSÃO}

Os resultados revelaram que as mães, ao se depararem com o filho na UTIN, vivenciaram sentimentos diversos, como o medo, a tristeza, a culpa e a saudade de ficar junto 
ao filho e de poder pegá-lo no colo. Essas sensações de impotência e insegurança para realizar um toque ou cuidado contribuíram para a sensação de incapacidade, e, muitas vezes, para o afastamento delas em relação ao recém-nascido. Contudo, as mães relataram confiança e segurança no cuidado dos profissionais com seus filhos.

A ansiedade das mães, causada pelo nascimento prematuro e necessidade de internação em UTIN, deve ser amenizada pelo cuidado humanizado e orientações da equipe de saúde, pois o entendimento da mãe sobre a real situação do bebê pode auxiliar a terapia e tornar possível levar o bebê para o domicílio com segurança para realização dos cuidados necessários, evitando internações recorrentes.

Assim, a sensibilização dos profissionais da equipe de saúde na UTIN, por meio de oficinas, é importante para desenvolver visão diferenciada sobre o binômio mãe-filho, auxiliando-os na formação de vínculo afetivo e proporcionando cuidado mais humano e holístico no processo de internação neonatal.

\section{REFERÊNCIAS}

1. Carmona EV, Vale IN, Ohara CVS, Abrão ACFV. Percepção materna quanto aos filhos recém-nascidos hospitalizados. Rev Bras Enferm. 2014 set-out;67(5):788-93.

2. Muñoz M, Poo AM, Baeza B, Bustos M L. Mother-newborn relational risk - Study of prevalence and associated variables. Rev Chil Pediatr. [Internet]. 2015 [cited 2017 Oct 29]; 86(1):25-31. Available from: https://www.ncbi.nlm.nih.gov/ pubmed/26223394

3. Vivian AG, Lopes RCS, Geara GB, Piccinini CA. "Eu fico comparando": expectativas maternas quanto ao segundo filho na gestação. Estud psicol [Internet]. 2013 [cited 2016 abr 12]; 30(1): 75-87. Available from: http://dx.doi.org/10.1590/ S0103-166X2013000100009
4. Veronez M, Borghesan NAB, Corrêa DAM, Higarashi IH. Vivência de mães de bebês prematuros do nascimento a alta: notas de diários de campo. Rev Gaúcha Enferm. [Internet]. 2017 [cied 2017 Out 31]; 38(2): e60911. Available from: http://www.scielo. br/scielo.php?script=sci_arttext\&pid=S1983$-14472017000200419 \&$ Ing=pt. Epub 20Jul-2017. http://dx.doi.org/10.1590/19831447.2017.02.60911.

5. Reis AT, Santos RS. Mothering the surgical newborn: foundations for nursing care. Rev Bras Enferm. [Internet]. 2013 [cited 2017 oct 24]; 66(1):110-5. Available from: http://www.scielo. br/scielo.php?script=sci_arttext\&pid=S0034$-71672013000100017 \&$ Ing=pt. http://dx.doi. org/10.1590/S0034-71672013000100017.

6. Medeiros FB de, Piccinini CA. Relação pai-bebê no contexto da prematuridade: gestação, internação do bebê e terceiro mês após a alta hospitalar. Estud Psicol. [Internet]. 2015 [cited 2017 Out 31]; 32(3): 475-485. Available from: $<$ http://www.scielo.br/scielo.php?script=sci_arttext\&pid=S0103$-166 \times 2015000300475 \&$ lng $=p t \& n r m=i s o>$. ISSN 0103-166X. http://dx.doi.org/10.1590/0103$-166 \times 2015000300012$.

7. Melo RCJ, Souza, IEO, Paula CC. Enfermagem neonatal: o sentido existencial do cuidado na Unidade de Terapia Intensiva. Rev Bras Enferm. 2013 set-out; 66(5): 656-62.

8. Bardin L. Análise de conteúdo. Ed. Edições 70. Lisboa, 2017.

9. Minayo MCS. O desafio do conhecimento. Pesquisa qualitativa em saúde. $11^{\mathrm{a} e d}$. São Paulo: HUCITEC/ABRASCO, 2014.

10. Hospital Universitário de Londrina. Hospital Universitário [Internet] 2017 [cited 2017 oct 24]. Available from: http://www.hu.uel.br/index. php?pagina $=29 \&$ pai $=7$

11. Haguette TMF. Metodologias qualitativas na sociologia. 14a.ed. Petrópolis: Vozes; 2011.

12. Zani AV, Golias AR, Martins ST, Parada CMG, Tonete VLP. Feelings experienced by the family of an at-risk newborn infant: integrative literature review. J Nurs UFPE on line. [Internet]. 2013 [cited 2016 apr 21]; 7(1):269-78. Available from: http:// www.revista.ufpe.br/revistaenfermagem/index. php/revista/article/view/2610/pdf_1915 
13. Raines, Deborah A. PhD, EdS, RN, ANEF. Mothers' Stressor as the Day of Discharge From the NICU Approaches. Advances in Neonatal Care. [Internet]. 2013 [cited 2016 apr 19]; 13(3):181-7. Available from: http://ovidsp.tx.ovid.com/sp-3.19.0a/ ovidweb.cgi

14. Balbino FS, Yamanaka Cl, Balieiro MMFG, Mandetta MA. Parent's support group as a transforming experience for families at a neonatal unit. Esc Anna Nery Rev Enferm. [Internet]. 2015 [cited 2016 abr. 28]; 19(2):297-302. Available from: http://www.scielo.br/pdf/ean/v19n2/1414-8145ean-19-02-0297.pdf

15. Brasil. Ministério da Saúde. Atenção humanizada ao recém-nascido de baixo peso - método mãe canguru. 2a ed. Brasília: Ministério da Saúde, 2013.

16. Zani AV, Tonete VLP, Parada CMGL. Maternal representations about the provision of care to newborns at risk: a collective discourse. Online Braz J Nurs. [Internet]. 2014 [cited 2016 apr 21]; 13(3): 321-31. Available from <http://www.objnursing. uff.br/index.php/nursing/article/view/4328

17. Perricone G, Morales MR, De Luca F, Carollo A, Maniscalco F, Caldas Luzeiro Jm, Polizzi C. Coping and parental role competence of mothers of preterm infant. Minerva Pediatr. [Internet]. 2014 [Cited 2016 apr 21]; 66(3): 177-86. Available from: http://pesquisa.bvsalud.org/portal/resource/pt/ mdl-24826974

18. Welch MG, et al. “Correction: Family Nurture Intervention (FNI): Methods and Treatment Protocol of a Randomized Controlled Trial in the NICU." BMC Pediatrics [Internet]. 2012 [cited 2016 apr 21]; 107. Available from: www.ncbi.nlm.nih.gov/pmc/ articles/PMC3459732

19. Russell G, Sawyer A, Rabe H, Abbott J, Gyte G, Duley $L$, et al. Parents' views on care of their very premature babies in neonatal intensive care units: a qualitative study. BMC Pediatr. [Internet]. 2014 [Cited 2017 Oct 29]; 10(1). Available from: https://www.ncbi.nlm.nih.gov/pmc/articles/ PMC4190336/

20. Nascimento CAD, Cartaxo CMB, Monteiro EMLM, Silva LMP, Souto CC, Leão ENC. Nurses' perception on parents of premature babies in the neonatal intensive care unit. Rev Rene. 2013; 14(4):811-20.

Todos os autores participaram das fases dessa publicação em uma ou mais etapas a seguir, de acordo com as recomendações do International Committe of Medical Journal Editors (ICMJE, 2013): (a) participação substancial na concepção ou confecção do manuscrito ou da coleta, análise ou interpretação dos dados; (b) elaboração do trabalho ou realização de revisão crítica do conteúdo intelectual; (c) aprovação da versão submetida. Todos os autores declaram para os devidos fins que são de suas responsabilidades o conteúdo relacionado a todos os aspectos do manuscrito submetido ao OBJN. Garantem que as questões relacionadas com a exatidão ou integridade de qualquer parte do artigo foram devidamente investigadas e resolvidas. Eximindo, portanto o OBJN de qualquer participação solidária em eventuais imbróglios sobre a matéria em apreço. Todos os autores declaram que não possuem conflito de interesses, seja de ordem financeira ou de relacionamento, que influencie a redação e/ou interpretação dos achados. Essa declaração foi assinada digitalmente por todos os autores conforme recomendação do ICMJE, cujo modelo está disponível em http://www. objnursing.uff.br/normas/DUDE_final_13-06-2013.pdf

Recebido: $17 / 08 / 2016$

Revisado: $24 / 10 / 2017$

Aprovado: $24 / 10 / 2017$ 